\title{
Inflammatory mechanisms involved in brain injury following cardiac arrest and cardiopulmonary resuscitation (Review)
}

\author{
YANXIAO XIANG ${ }^{1,2}$, HUA ZHAO $^{3}$, JIALI WANG $^{4-7}$, LUETAO ZHANG $^{4-7}$, ANCHANG LIU $^{1}$ and YUGUO CHEN ${ }^{2,4-7}$ \\ Departments of ${ }^{1}$ Clinical Pharmacy, ${ }^{2}$ Emergency and ${ }^{3}$ Orthopedics, Qilu Hospital, Shandong University; \\ ${ }^{4}$ Chest Pain Center, Qilu Hospital, Shandong University; ${ }^{5}$ Institute of Emergency and Critical Care Medicine, \\ Shandong University; ${ }^{6}$ Key Laboratory of Emergency and Critical Care Medicine of Shandong Province; \\ ${ }^{7}$ Key Laboratory of Cardiovascular Remodeling and Function Research, Chinese Ministry of Education and \\ Chinese Ministry of Public Health, Qilu Hospital, Shandong University, Jinan, Shandong 250012, P.R. China
}

Received February 2, 2016; Accepted April 25, 2016

DOI: $10.3892 /$ br.2016.677

\begin{abstract}
Cardiac arrest (CA) is a leading cause of fatality and long-term disability worldwide. Recent advances in cardiopulmonary resuscitation (CPR) have improved survival rates; however, the survivors are prone to severe neurological injury subsequent to successful CPR following CA. Effective therapeutic options to protect the brain from $\mathrm{CA}$ remain limited, due to the complexities of the injury cascades caused by global cerebral ischemia/reperfusion (I/R). Although the precise mechanisms of neurological impairment following CA-initiated I/R injury require further clarification, evidence supports that one of the key cellular pathways of cerebral injury is inflammation. The inflammatory response is orchestrated by activated glial cells in response to I/R injury. Increased release of danger-associated molecular pattern molecules and cellular dysfunction in activated microglia and astrocytes contribute to ischemia-induced cytotoxic and pro-inflammatory cytokines generation, and ultimately to delayed death of neurons. Furthermore, cytokines and adhesion molecules generated within activated microglia, as well as astrocytes, are involved in the innate immune response; modulate influx of peripheral immune and inflammatory cells into the brain, resulting in neurological injury. The present review discusses the molecular aspects of immune and inflammatory mechanisms in global cerebral I/R injury following CA and CPR, and the
\end{abstract}

Correspondence to: Dr Yuguo Chen, Department of Emergency, Qilu Hospital, Shandong University, 107 Wenhua West Road, Jinan, Shandong 250012, P.R. China

E-mail: chen919085@126.com

Dr Anchang Liu, Department of Clinical Pharmacy, Qilu Hospital, Shandong University, 107 Wenhua West Road, Jinan, Shandong 250012, P.R. China

E-mail: anchang.liu@gmail.com

Key words: neurological impairment, inflammatory response, microglia, astrocyte, cardiac arrest, cardiopulmonary resuscitation potential therapeutic strategies that target neuroinflammation and the innate immune system.

\section{Contents}

1. Introduction

2. Cerebral I/R damage following CA and resuscitation

3. Role of inflammatory cells in cerebral injury following CA and resuscitation

4. Role of cytokines in cerebral injury following CA and resuscitation

5. Role of chemokines in cerebral injury following CA and resuscitation

6. Role of cellular adhesion molecules in cerebral injury following CA and resuscitation

7. Development of neuroprotective interventions following $\mathrm{CA}$ and resuscitation

8. Conclusion

\section{Introduction}

Cardiac arrest (CA) remains a leading cause of fatality and permanent disability worldwide. Patient care guidelines have been continuously developed and modified so as to increase the proportion of individuals who survive CA $(1,2)$. The recommended treatment is to start cardiopulmonary resuscitation (CPR), including chest compressions and external defibrillation, immediately to achieve return of spontaneous circulation (ROSC) thereby restoring organ perfusion $(3,4)$. Due to the profound impact of advances in CPR, the survival rates to hospital discharge from in hospital CA has improved significantly over the last decade (5). However, nearly $50 \%$ of the CA victims who do survive and undergo hospital discharge suffer from moderate to severe long-term neurological deficits that significantly affect their quality of life $(6,7)$. Despite advances in CPR, the persistent neurological deficits, such as neurocognitive impairment, learning and memory difficulties, and other neurological disorders were identified, influencing the American Heart Association (AHA) 
to emphasize cerebral injury associated with CA and CPR by proposing 'cardiopulmonary-cerebral resuscitation' in its 2000 Guidelines for Cardiopulmonary Resuscitation and Emergency Cardiovascular Care (8). Over decades, however, no specific drug therapy has been shown to improve the neurological outcome following CA and CPR (9).

CA directly causes global cerebral ischemia, which in turn triggers selective, delayed, neuronal cell death. The first aim of CPR is to reestablish sufficient circulation to supply the brain and heart with oxygen. However, emerging evidence supports that initial successful CPR could cause extensive ischemia/reperfusion (I/R) injury to the brain and other vital organs that is closely correlated with poor outcome (7). Although the principal pathophysiology regarding cerebral I/R injury following CA remains to be elucidated, it is well accepted that one of the definitive, but understudied, mechanisms of cerebral I/R injury is inflammation (10). It is characterized by activation of glial cells, influx of peripheral immune and inflammatory cells, high concentrations of reactive oxygen species (ROS) and release of proinflammatory mediators, including cytokines and adhesion molecules (11-13). The inflammatory process collectively inflicts lethal damage to neurons, exacerbates endothelial dysfunction and vasomotor dysregulation and disrupts the blood-brain barrier (BBB), induces edema, leading to tissue-level hypoxia and subsequent neurological damage (14). Despite a more comprehensive understanding regarding the mechanisms of cerebral injury, currently no clinically proven pharmacological therapy data against cerebral I/R damage during CA and CPR are available (15). Increasing evidence reveals that suppressing the inflammatory process facilitates neuroprotection and has potential for use in the clinical treatment of cerebral I/R damage regarding CA (16).

The aim of the present review is to evaluate the specific aspects of the immune and inflammatory mechanisms underlying cerebral I/R injury regarding $\mathrm{CA}$ and $\mathrm{CPR}$, and furthermore, this study reviews the potential anti-inflammatory targets in brain injury during CPR and the post-resuscitation phase. Overall, the prospects for a secure clinical strategy to improve neurological outcome following $\mathrm{CA}$ remain promising.

\section{Cerebral I/R damage following $\mathrm{CA}$ and resuscitation}

Brain injury from CA and post-resuscitation comes in stages. Within seconds of global cerebral ischemia and hypoxia, cerebral activities are compromised, and within minutes, the ischemic cascade is rapidly initiated, which consists of a series of biochemical events, including depletion of adenosine triphosphate and glucose, $\mathrm{Na}^{+} / \mathrm{K}^{+}$pump failure and loss of cell structural integrity $(17,18)$. These events, which subsequently lead to mitochondrial damage and intracellular calcium overload, further exacerbate immediate cellular necrosis or apoptosis when coupled with increased levels of arachidonic acid, glutamate and other toxic excitatory neurotransmitters (19). Restoration of oxygenation, corresponding to reperfusion during $\mathrm{CA}$, limits ongoing hypoxic damage, which is crucial for restoring normal function. However, it can paradoxically cause continued cellular damage and death, which occurs over the subsequent hours and days after successful resuscitation. During reperfusion injury, reoxygenation promotes the generation of ROS and nitrogen metabolites within the active microglia and astrocytes; migration of peripheral macrophages, monocytes and neutrophils; release of cytokines and adhesion molecules by the inflammatory cells, which eventually precipitate lethal damage to neurons, oligodendrocytes and the cerebrovascular endothelium, and disruption of BBB (20).

Furthermore, the innate immune system may have a critical role in cerebral reperfusion injury (21). It has been demonstrated that the brain and innate immune system are engaged in bidirectional crosstalk. In a manner similar to the response defending against pathogen invaders, the cerebral inflammatory cascade comprises an increase of neutrophil recruitment and peripheral macrophages infiltration, activation and migration of microglia, also known as 'brain macrophages', and release of pro-inflammatory stimuli within the brain $(20,22)$. Additionally, microglia and astrocytes express a wide variety of receptors of innate immunity, such as toll-like receptors (TLRs) (23). When an ischemic event occurs, the normally immune-privileged brain environment collapse, danger-associated molecular pattern molecules released by cellular injury can be recognized as invaders by immune cells in terms to induce the activation of TLRs and triggers the activation process of nuclear factor- $\kappa \mathrm{B}$ and signal transducer and activator of transcription 3 signaling pathways, which are linked to the transcription of numerous proinflammatory genes $(24,25)$. As a result, encoded cytokines, chemokines and proteins of the complement cascade are upregulated in the cerebral tissue, and consequently, the generation of adhesion molecules on the endothelial cell surface is induced. The described neuroinflammatory changes ultimately lead to neurological damage following $\mathrm{CA}$ and CPR.

\section{Role of inflammatory cells in cerebral injury following $\mathrm{CA}$ and resuscitation}

Microglia-innate immune cells of the brain. Microglial cells, the resident macrophages of the brain, are activated immediately following brain injury and have numerous immunological characteristics with blood-derived monocyte/macrophages (26-28). Following ischemia, microglia undergo phenotypic transformation to an 'activated' phenotype which can release various substances, many of which are cytoprotective or cytotoxic (29). Microglia also have a functional role in the phagocytosis of cell debris and in the release of neurotrophic factors, such as brain-derived neurotrophic factor, insulin-like growth factor I and several other growth factors. Acutely activated microglial cells in response to ischemia produce several pro-inflammatory cytokines, such as interleukin-6 (IL-6), IL-1 $\beta$ and tumor necrosis factor- $\alpha$ $(\mathrm{TNF}-\alpha)$, as well as other potential cytotoxic molecules including ROS, nitric oxide (NO) and prostanoids $(11,30)$. This initial innate immune response will be evoked rapidly in almost any disruption or loss of brain homeostasis, and it is perceived as a first-line defense against an infection or to blunt further damage following an injury. In cerebral injury following $\mathrm{CA}$ and resuscitation, however, this initial response may be maladaptive (31). 
Resident microglia are activated within minutes of hypoxia onset and require hours to days to fully develop. Following the resuscitation, reoxygenation promotes a continuous release of signals, including ROS and NO, from microglia (30). These signals also trigger infiltration of peripheral immune cells, such as neutrophils, macrophages and T lymphocytes, to the injured area, all these cell types can in turn affect microglial activation and contribute to ongoing secondary neuronal injury $(26,27,30)$.

The special characteristic of microglia is in its striking ability to multiply and migrate in response to cerebral injury $(32,33)$. Microglial proliferation has been implicated in the onset and progression of cerebral I/R damage (34). Active microglia express a variety of biologically active substances, which induce microglia proliferation (35). A rapid increase in the number of microglia at an injured area is associated with the influx of peripheral immune cells and migration of resident microglia from other sections of the brain (36).

Astrocytes. It is well documented that astrocytes interact with and support neighboring neurons (37). Under hypoxic stress, astrocytes not only release neuroprotective molecules, including metabolic substrates, antioxidants and neurotrophic factors, but also produce a myriad of cytokines, a number of which have dual proinflammatory and anti-inflammatory effects $(12,38)$. In response to $I / R$ injury, astrocytes were activated early ( $2 \mathrm{~h}$ ) after reperfusion but confined to the area where neurons started to show degeneration and death hours to days later. This finding demonstrated the importance of astrocytes in delayed neurological damage following I/R injury. Consideration of the role of astrocytes may be an ideal factor for potential neuroprotective strategies $(39,40)$.

Experimental data indicates that astrocyte mitochondria are an important target of I/R insults regarding CA $(41,42)$. Within a few hours of reperfusion, increased ROS production from mitochondrial respiratory chain results in mitochondrial dysfunction in astrocytes, contributes to the loss of glutamate transporter 1 and ultimately to delayed death of neurons $(43,44)$.

Neutrophils. Within a few hours after ischemia onset, peripheral leukocytes adhere to vascular endothelial cell and migrate into damaged brain tissue with the subsequent release of pro-inflammatory molecules and secondary injury in the post-ischemic area. Neutrophils are the earliest leukocyte subtype to show substantial upregulation and to infiltrate areas of brain ischemia $(45,46)$. Similar to in peripheral tissues, the trans-endothelial migration of neutrophils into the brain also appear to demand cellular adhesion molecules (CAMs), including intercellular adhesion molecule 1 (ICAM-1) and P-selectin (47,48). Deficiency of ICAM-1 and P-selectin has been demonstrated to reduce the infarct size and formation of brain edema in mouse models of ischemic stroke $(49,50)$. Infiltrating neutrophils, as well as microglia and macrophages, are also able to produce additional ROS, pro-inflammatory cytokines, including IL- $6, \mathrm{IL}-1 \beta$ and TNF- $\alpha$, and chemokines, such as monocyte chemoattractant protein-1 (MCP-1) and IL-8. By these molecules, infiltrating neutrophils amplify a cerebral inflammatory response that may exacerbate post-ischemic brain damage $(49,51,52)$. Furthermore, infiltrating neutrophils are the primary source of enhanced matrix metalloproteinase 9 activity in the ischemic brain, which is a critical mechanism underlying the breakdown of the $\mathrm{BBB}$ and the exacerbation of neurological injury (53).

Tymphocytes. Accumulating evidence supports that the infiltration of $\mathrm{T}$ lymphocytes significantly contributes to the pathogenesis of cerebral I/R injury, and different classes of $\mathrm{T}$ lymphocytes have differential roles in response to I/R-mediated adaptive immunity $(54,55)$. It is generally known that there are two subtypes of T lymphocytes: Cluster of differentiation $4^{+}\left(\mathrm{CD}^{+}\right)$T-helper $(\mathrm{Th})$ cells and CD8 ${ }^{+}$cytotoxic T cells. The Th cell subset comprises Th1, Th2, Th17 and Th40 and regulatory $\mathrm{T}$ cells $(56,57)$.

Studies using a mouse model of CA/CPR show that CA and resuscitation stimulates rapid infiltrations of $\mathrm{CD}^{+}$and $\mathrm{CD}^{+}$ $\mathrm{T}$ cells to the ischemic brain area, which were observed to contribute to the inflammatory and thrombogenic responses, brain infarction and neurological deficit (58). During the $\mathrm{I} / \mathrm{R}$ injury process, $\mathrm{CD}^{+}$cytotoxic $\mathrm{T}$ cells directly serve to promote the immune and inflammatory responses through the release of cytokines, including IFN- $\gamma$ and TNF- $\alpha$ (59). CD4 ${ }^{+}$ Th cells have no cytotoxic activity themselves, but instead aid in the activation of other immune cells, including $\mathrm{CD}^{+}$cytotoxic T cells (60). Experimental data also indicates that $\mathrm{CD}^{+}$ $\mathrm{T}_{\text {cell }}{ }^{(-)}$and $\mathrm{CD}^{+} \mathrm{T}$ cell ${ }^{(--)}$mice are protected from hippocampal CA1 neuronal cell death, compared with wild-type mice following CPR-induced ischemic brain damage (58).

\section{Role of cytokines in cerebral injury following $\mathrm{CA}$ and resuscitation}

Cerebral injury is correlated to the abundant synthesis of inflammatory cytokines during CA and resuscitation $(61,62)$. In the brain, cytokines are not only produced by the cells of the immune system, but also expressed in resident brain cells, including neurons and glia (63). In addition, cytokines released by peripheral immune cells are involved in neuroinflammation and their inhibition or deficiency is associated with reduced injury (64-66).

The majority of investigations regarding cytokines associated with inflammation in ischemic cerebral injury mostly focuses on IL-6, IL-1 $\beta$, IL-10, IL-20, TNF- $\alpha$ and transforming growth factor- $\beta$ (TGF- $\beta$ ). Among these cytokines, IL-1 $\beta$ and TNF- $\alpha$ appear to exacerbate cerebral damage; however, TGF- $\beta$ and IL-10 may be neuroprotective $(67,68)$. Increased synthesis of pro-inflammatory cytokines and decreased production of the anti-inflammatory IL-10 are correlated with larger infarct volume and poorer neurological outcome (69).

In the reperfusion period, $\mathrm{TNF}-\alpha$ levels in the ischemic area elevate markedly and persist at a high level following reperfusion (70). TNF- $\alpha$ expression occurred initially in neurons, and subsequently in glia cells, including microglia and astrocytes as well as in the peripheral immune cells (71-73). Clinical studies have shown that TNF- $\alpha$-positive cells localize in all ischemic brains of patients who experienced a severe stroke 3 days post-stroke and remain $<15$ months post-stroke, and the majority of the increased TNF- $\alpha$ are derived from microglia and macrophages $(74,75)$. TNF- $\alpha$ levels in the serum of stroke patents are elevated within $6 \mathrm{~h}$ and stay increased for 10 days post-stroke compared to the controls $(76,77)$. 
IL-1 $\beta$ levels increased significantly in the reperfusion period and remained at high levels for days after reperfusion $(78,79)$. IL-1 $\beta$-positive staining was observed in the ischemic regions of the cortex within 16-24 h after stroke (80). An elevated level of IL-1 $\beta$ can potentiate inflammation by activating microglia and induce the infiltration of peripheral leukocytes by increasing the expression of adhesion molecules on endothelial cells; these events are associated with worsening of the infarct severity and progressive neurodegeneration (81-83). In addition to its role as a pro-inflammatory mediator, IL-1 $\beta$ can also elevate the expression of other pro-inflammatory cytokines, such as IL- 6 and TNF- $\alpha$, which can be upregulated following cerebral ischemia (84).

IL-10 exerts potential anti-inflammatory effects by inhibiting IL-1 and TNF- $\alpha$, and by suppressing cytokine receptor expression and receptor activation as well (85). As a consequence, IL-10 could confer a neuroprotective effect in acute ischemic stroke. In a rat model of cerebral I/R injury, administration of IL-10 appeared to decrease the infarct volume significantly from $30 \mathrm{~min}$ to $3 \mathrm{~h}$ post-ischemia compared to the control animals (67).

\section{Role of chemokines in cerebral injury following $\mathrm{CA}$ and resuscitation}

In the brain, chemokines, such as IL-8 and MCP-1, are primarily expressed on the neurons and glial cells (63). Circulation chemokines are mainly derived from the immune system, such as neutrophils and macrophages (64). Chemokines are involved in conveying pro-inflammatory signals and inducing immune cells to recruit to the injured tissues. Elevated levels of chemokines, such as MCP-1 (or CCL2) and inflammatory protein-1 $\alpha$ (MIP-1 $\alpha$ or CCL3), following ischemic injury have been correlated with an increase of peripheral neutrophils infiltration. CCL2 and CCL3 upregulation has been found in the early hours after ischemic stroke $(86,87)$. Intracerebroventricular injection of CCL3 enlarged the infarct territory following transient focal ischemia in rats, CCL2-deficient mice had a smaller infarct size and decreased infiltration of inflammatory cells $(86,88)$. Mice without the chemokine receptor CCR2 are protected against ischemia-reperfusion injury (89).

\section{Role of cellular adhesion molecules in cerebral injury following $\mathrm{CA}$ and resuscitation}

Clinical investigations and animal studies have shown that CAMs are critical participants in the cerebral injury following CA/CPR $(49,90)$. In the ischemic brain, the high level of pro-inflammatory cytokines induces the cerebral endothelial cells to express CAMs that mediate the recruitment of leukocytes to the injured region. Three well-known CAMs, ICAM-1, and P- and E-selectin, are highly expressed at ischemic areas and promote the firm adhesion and migration of neutrophils into damage brain tissues, thereby contributing to neuroinflammation-mediated neurological injury (91-93). In response to $\mathrm{I} / \mathrm{R}$ injury, $\mathrm{P}$-selectin can be detected as early as $15 \mathrm{~min}$ after reperfusion, while E-selectin expression is observed from $2 \mathrm{~h}$ after ischemia. Increased expression of ICAM-1 can be observed within hours after ischemia onset $(94,95)$. Compared to wild-type mice, ICAM-1-knockout mice exhibit a reduction in neutrophil infiltration, smaller infarct size, improved cerebral blood flow and lower mortality following I/R injury (47,96). In a model of cerebral I/R, P-selectin-knockout mice exhibit less infarct volume, better functional outcome and an improved return of cerebral blood flow following ischemia (48). E-selectin blockade with specific antibodies $90 \mathrm{~min}$ after ischemia onset reduce neutrophil infiltration and infarct volume (93).

\section{Development of neuroprotective interventions following $\mathrm{CA}$ and resuscitation}

General. CA/CPR-induced neurological damage is a progressive process that can develop over a long time following the initial injury (15). As aforementioned, strong evidence now exists to suggest that neuroinflammation continues for days and months, and contributes to the neurological damage that ultimately determines the impaired recovery following CA and CPR (16). This suggests that the neuroprotective anti-inflammatory treatments discussed in the following are promising strategies for $\mathrm{CA}$ and resuscitation intervention.

Therapeutic hypothermia (TH). Several recent multicenter, randomized trials report that $\mathrm{TH}$ confers significant neuroprotective effects and reduces mortality by $>25 \%$ when applied for 12-24 h after successfully resuscitated ventricular fibrillation (VF) arrest in adults (97). On the basis of these studies, the AHA published guidelines and awarded the highest level of recommendation for the use of hypothermia in the treatment of patients successfully resuscitated from VF-induced CA. Currently, at 6 months after CA, 55 and $39 \%$ of the patients treated with or without $\mathrm{TH}$, respectively, have a favorable neurological outcome. The proposed mechanism underlying the protective effect of TH has generally been attributed to its preservation of metabolic substrates, alteration of cerebral blood flow and prevention of excitatory amino acid accumulation (98). A previous study suggested that TH following CA did not alter serum inflammatory cytokines, including TNF- $\alpha$, IL-2, IL-10 and MCP-1, demonstrating that the beneficial effects of $\mathrm{TH}$ do not arise from alleviation of the inflammatory response (99). Therefore, adjunct treatment targeted to inflammation and immune dysregulation are urgently required to improve the overall efficacy of TH (100).

Minocycline. Minocycline, a semisynthetic tetracycline derivative, has been reported to be neuroprotective against post-arrest global cerebral I/R injury by exerting anti-inflammatory effects, including inhibition of the activation and proliferation of microglia, migration of neutrophils, release of proinflammatory cytokines and chemokines (101). Minocycline administration diminishes infarct volume and improves functional recovery following experimental stroke, and even provides clear protection when the treatment is started $4 \mathrm{~h}$ after the onset of stroke $(102,103)$. Furthermore, the outcomes for stroke patients treated with minocycline within 6 to $24 \mathrm{~h}$ after ischemia are significantly better compared to the placebo (104).

Molecular hydrogen $\left(\mathrm{H}_{2}\right) . \mathrm{H}_{2}$ is a new popular therapeutic agent for cerebral I/R injury treatment (105). In two animal 
models of CA/CPR-induced global I/R injury, the beneficial effects of $\mathrm{H}_{2}$ treatment were associated with the antioxidant and anti-inflammation effects $(106,107)$.

Statins. Statins are the 3-hydroxy-3-methylglutaryl coenzyme, which are reductase inhibitors that have been shown to reduce infarct size in animal models of stroke. Statins may provide pleiotropic neuroprotective effects following cerebral ischemia that are independent of cholesterol lowering, including attenuation of inflammatory responses, amelioration of oxidant stress and improvement of endothelial function (108).

\section{Conclusion}

$\mathrm{CA}$ is a devastating disease process with neurological injury accounting for poor outcome following ROSC. Accordingly, a collaborative effort to resolve the mechanisms underlying neurological injury could potentially enhance our understanding of the pathobiology of brain resuscitation following CA. Emerging preclinical, as well as recent human clinical evidence, suggests that activation of inflammatory cascade and the immune system have critical roles in the pathogenesis of neurological damage following CA/CPR. An increasing number of anti-inflammatory and immunomodulatory compounds have shown feasible potential for the neuroprotective effects in preclinical settings. However, a more efficient development of treatments targeting the elements of these injury cascades is required for an improved outcome and quality of life for CA patients.

\section{Acknowledgements}

The present study was supported by the National Natural Science Foundation of China (grant nos. 81503061, 81570401, 81170136, 81300103 and 81571934), Taishan Scholar Program of Shandong Province (grant no. ts20130911), Specialized Research Fund for the Doctoral Program of Higher Education (grant no. 20130131110048), Key Technology Research and Development Program of Science and Technology of Shandong Province (grant no. 2014kjhm0102), Department of Science and Technology of Shandong Province (grant no. 2014GGE27492) and the Fundamental Research Funds of Shandong University (grant no. 2014QLKY04).

\section{References}

1. Nolan JP, Soar J, Zideman DA, Biarent D, Bossaert LL, Deakin C, Koster RW, Wyllie J and Böttiger B; ERC Guidelines Writing Group: European Resuscitation Council Guidelines for Resuscitation 2010 Section 1. Executive summary. Resuscitation 81: 1219-1276, 2010.

2. Field JM,Hazinski MF, Sayre MR, Chameides L, SchexnayderSM, Hemphill R, Samson RA, Kattwinkel J, Berg RA, Bhanji F, et al: Part 1: executive summary: 2010 American Heart Association Guidelines for Cardiopulmonary Resuscitation and Emergency Cardiovascular Care. Circulation 122 (Suppl 3): S640-S656, 2010.

3. Abella BS, Alvarado JP, Myklebust H, Edelson DP, Barry A, O'Hearn N, Vanden Hoek TL and Becker LB: Quality of cardiopulmonary resuscitation during in-hospital cardiac arrest. JAMA 293: 305-310, 2005

4. van Alem AP, Vrenken RH, de Vos R, Tijssen JG and Koster RW: Use of automated external defibrillator by first responders in out of hospital cardiac arrest: Prospective controlled trial. BMJ 327: 1312,2003
5. Girotra S, Spertus JA, Li Y, Berg RA, Nadkarni VM and Chan PS; American Heart Association Get With the Guidelines - Resuscitation Investigators: Survival trends in pediatric in-hospital cardiac arrests: An analysis from Get With the Guidelines-Resuscitation. Circ Cardiovasc Qual Outcomes 6: 42-49, 2013.

6. Young GB: Clinical practice. Neurologic prognosis after cardiac arrest. N Engl J Med 361: 605-611, 2009.

7. Go AS, Mozaffarian D, Roger VL, Benjamin EJ, Berry JD, Blaha MJ, Dai S, Ford ES, Fox CS, Franco S, et al; American Heart Association Statistics Committee and Stroke Statistics Subcommittee: Heart disease and stroke statistics - 2014 update: A report from the American Heart Association. Circulation 129: e28-e292, 2014.

8. No authors listed: Part 1: Introduction to the International Guidelines 2000 for CPR and ECC: A consensus on science. Circulation 102 (Suppl 8): I1-I11, 2000.

9. Papastylianou A and Mentzelopoulos S: Current pharmacological advances in the treatment of cardiac arrest. Emerg Med Int 2012: 815857, 2012.

10. Liu F and McCullough LD: Inflammatory responses in hypoxic ischemic encephalopathy. Acta Pharmacol Sin 34: 1121-1130, 2013.

11. Lucas SM, Rothwell NJ and Gibson RM: The role of inflammation in CNS injury and disease. Br J Pharmacol 147 (Suppl 1): S232-S240, 2006.

12. Swanson RA, Ying W and Kauppinen TM: Astrocyte influences on ischemic neuronal death. Curr Mol Med 4: 193-205, 2004.

13. Wong $\mathrm{CH}$ and Crack PJ: Modulation of neuro-inflammation and vascular response by oxidative stress following cerebral ischemia-reperfusion injury. Curr Med Chem 15: 1-14, 2008.

14. Iadecola $\mathrm{C}$ and Anrather J: The immunology of stroke: From mechanisms to translation. Nat Med 17: 796-808, 2011.

15. Dezfulian C, Shiva S, Alekseyenko A, Pendyal A, Beiser DG, Munasinghe JP, Anderson SA, Chesley CF, Vanden Hoek TL and Gladwin MT: Nitrite therapy after cardiac arrest reduces reactive oxygen species generation, improves cardiac and neurological function, and enhances survival via reversible inhibition of mitochondrial complex I. Circulation 120: 897-905, 2009.

16. Lambertsen KL, Clausen BH, Babcock AA, Gregersen R, Fenger C, Nielsen HH, Haugaard LS, Wirenfeldt M, Nielsen M, Dagnaes-Hansen F, et al: Microglia protect neurons against ischemia by synthesis of tumor necrosis factor. J Neurosci 29: 1319-1330, 2009

17. Polderman KH: Mechanisms of action, physiological effects, and complications of hypothermia. Crit Care Med 37 (Suppl 7): S186-S202, 2009.

18. Arrich J, Holzer M, Havel C, Müllner M and Herkner H: Hypothermia for neuroprotection in adults after cardiopulmonary resuscitation. Cochrane Database Syst Rev 9: CD004128, 2012.

19. Soleimanpour H, Khoshnudi F, Movaghar MH and Ziapour B: Improvement of decerebrate status in a hanged child following emergent tracheostomy. Pak J Biol Sci 13: 1164-1165, 2010.

20. Kvietys PR and Granger DN: Role of reactive oxygen and nitrogen species in the vascular responses to inflammation. Free Radic Biol Med 52: 556-592, 2012.

21. Steinman L: Elaborate interactions between the immune and nervous systems. Nat Immunol 5: 575-581, 2004.

22. Kalogeris T, Baines CP, Krenz M and Korthuis RJ: Cell biology of ischemia/reperfusion injury. Int Rev Cell Mol Biol 298: 229-317, 2012.

23. Farina C, Aloisi F and Meinl E: Astrocytes are active players in cerebral innate immunity. Trends Immunol 28: 138-145, 2007.

24. Medzhitov R, Preston-Hurlburt P and Janeway CA Jr: A human homologue of the Drosophila Toll protein signals activation of adaptive immunity. Nature 388: 394-397, 1997.

25. del Zoppo G, Ginis I, Hallenbeck JM, Iadecola C, Wang X and Feuerstein GZ: Inflammation and stroke: Putative role for cytokines, adhesion molecules and iNOS in brain response to ischemia. Brain Pathol 10: 95-112, 2000.

26. Aloisi F: Immune function of microglia. Glia 36: 165-179, 2001.

27. Nakajima K and Kohsaka S: Microglia: Activation and their significance in the central nervous system. J Biochem 130: 169-175, 2001.

28. Schilling M, Besselmann M, Leonhard C, Mueller M, Ringelstein EB and Kiefer R: Microglial activation precedes and predominates over macrophage infiltration in transient focal cerebral ischemia: A study in green fluorescent protein transgenic bone marrow chimeric mice. Exp Neurol 183: 25-33, 2003 . 
29. Stoll G, Jander S and Schroeter M: Inflammation and glial responses in ischemic brain lesions. Prog Neurobiol 56: 149-171, 1998.

30. Yenari MA, Kauppinen TM and Swanson RA: Microglial activation in stroke: Therapeutic targets. Neurotherapeutics 7: 378-391, 2010

31. Kettenmann H, Hanisch UK, Noda M and Verkhratsky A: Physiology of microglia. Physiol Rev 91: 461-553, 2011.

32. Ladeby R, Wirenfeldt M, Dalmau I, Gregersen R, García-Ovejero D, Babcock A, Owens T and Finsen B: Proliferating resident microglia express the stem cell antigen CD34 in response to acute neural injury. Glia 50: 121-131, 2005.

33. Ladeby R, Wirenfeldt M, Garcia-Ovejero D, Fenger C Dissing-Olesen L, Dalmau I and Finsen B: Microglial cell population dynamics in the injured adult central nervous system. Brain Res Brain Res Rev 48: 196-206, 2005.

34. Denes A, Vidyasagar R, Feng J, Narvainen J, McColl BW, Kauppinen RA and Allan SM: Proliferating resident microglia after focal cerebral ischaemia in mice. J Cereb Blood Flow Metab 27: 1941-1953, 2007.

35. Sawada M, Suzumura A, Yamamoto H and Marunouchi T: Activation and proliferation of the isolated microglia by colony stimulating factor-1 and possible involvement of protein kinase $\mathrm{C}$. Brain Res 509: 119-124, 1990

36. Schöbitz B, de Kloet ER, Sutanto W and Holsboer F: Cellular localization of interleukin $6 \mathrm{mRNA}$ and interleukin 6 receptor mRNA in rat brain. Eur J Neurosci 5: 1426-1435, 1993.

37. Nedergaard M, Ransom B and Goldman SA: New roles for astrocytes: Redefining the functional architecture of the brain. Trends Neurosci 26: 523-530, 2003

38. Ransom B, Behar T and Nedergaard M: New roles for astrocytes (stars at last). Trends Neurosci 26: 520-522, 2003.

39. Matsumoto S, Matsumoto M, Yamashita A, Ohtake K, Ishida K, Morimoto $\mathrm{Y}$ and Sakabe T: The temporal profile of the reaction of microglia, astrocytes, and macrophages in the delayed onset paraplegia after transient spinal cord ischemia in rabbits. Anesth Analg 96: 1777-1784, 2003. table of contents

40. Nedergaard M and Dirnagl U: Role of glial cells in cerebral ischemia. Glia 50: 281-286, 2005.

41. Fiskum G, Danilov CA, Mehrabian Z, Bambrick LL, Kristian T, McKenna MC, Hopkins I, Richards EM and Rosenthal RE: Postischemic oxidative stress promotes mitochondrial metabolic failure in neurons and astrocytes. Ann N Y Acad Sci 1147: 129-138, 2008

42. Bambrick L, Kristian T and Fiskum G: Astrocyte mitochondrial mechanisms of ischemic brain injury and neuroprotection. Neurochem Res 29: 601-608, 2004.

43. Lin MT and Beal MF: Mitochondrial dysfunction and oxidative stress in neurodegenerative diseases. Nature 443: 787-795, 2006.

44. Ouyang YB, Voloboueva LA, Xu LJ and Giffard RG: Selective dysfunction of hippocampal CA1 astrocytes contributes to delayed neuronal damage after transient forebrain ischemia J Neurosci 27: 4253-4260, 2007.

45. Shichita T, Sugiyama Y, Ooboshi H, Sugimori H, Nakagawa R, Takada I, Iwaki T, Okada Y, Iida M, Cua DJ, et al: Pivotal role of cerebral interleukin-17-producing gammadeltaT cells in the delayed phase of ischemic brain injury. Nat Med 15: 946-950 2009

46. Price CJ, Menon DK, Peters AM, Ballinger JR, Barber RW, Balan KK, Lynch A, Xuereb JH, Fryer T, Guadagno JV, et al: Cerebral neutrophil recruitment, histology, and outcome in acute ischemic stroke: An imaging-based study. Stroke 35: 1659-1664 2004

47. Connolly ES Jr, Winfree CJ, Springer TA, Naka Y, Liao H, Yan SD, Stern DM, Solomon RA, Gutierrez-Ramos JC and Pinsky DJ: Cerebral protection in homozygous null ICAM-1 mice after middle cerebral artery occlusion. Role of neutrophi adhesion in the pathogenesis of stroke. J Clin Invest 97: 209-216, 1996.

48. Connolly ES Jr, Winfree CJ, Prestigiacomo CJ, Kim SC, Choudhri TF, Hoh BL, Naka Y, Solomon RA and Pinsky DJ: Exacerbation of cerebral injury in mice that express the P-selectin gene: Identification of P-selectin blockade as a new target for the treatment of stroke. Circ Res 81: 304-310, 1997.

49. Yilmaz $\mathrm{G}$ and Granger DN: Cell adhesion molecules and ischemic stroke. Neurol Res 30: 783-793, 2008.

50. Ishikawa M, Stokes KY, Zhang JH, Nanda A and Granger DN: Cerebral microvascular responses to hypercholesterolemia: Roles of NADPH oxidase and P-selectin. Circ Res 94: 239-244, 2004 .
51. Amantea D, Nappi G, Bernardi G, Bagetta G and Corasaniti MT: Post-ischemic brain damage: Pathophysiology and role of inflammatory mediators. FEBS J 276: 13-26, 2009.

52. Kriz J: Inflammation in ischemic brain injury: Timing is important. Crit Rev Neurobiol 18: 145-157, 2006.

53. Ajmo CT Jr, Collier LA, Leonardo CC, Hall AA, Green SM, Womble TA, Cuevas J, Willing AE and Pennypacker KR: Blockade of adrenoreceptors inhibits the splenic response to stroke. Exp Neurol 218: 47-55, 2009.

54. Shigematsu T, Wolf RE and Granger DN: T-lymphocytes modulate the microvascular and inflammatory responses to intestinal ischemia-reperfusion. Microcirculation 9: 99-109, 2002.

55. Ysebaert DK, De Greef KE, De Beuf A, Van Rompay AR, Vercauteren S, Persy VP and De Broe ME: T cells as mediators in renal ischemia/reperfusion injury. Kidney Int 66: 491-496, 2004.

56. Brait VH, Arumugam TV, Drummond GR and Sobey CG: Importance of T lymphocytes in brain injury, immunodeficiency, and recovery after cerebral ischemia. J Cereb Blood Flow Metab 32: 598-611, 2012.

57. Vaitaitis GM and Wagner DH Jr: High distribution of CD40 and TRAF2 in Th40 T cell rafts leads to preferential survival of this auto-aggressive population in autoimmunity. PLoS One 3: e2076, 2008.

58. Deng G, Carter J, Traystman RJ, Wagner DH and Herson PS: Pro-inflammatory T-lymphocytes rapidly infiltrate into the brain and contribute to neuronal injury following cardiac arrest and cardiopulmonary resuscitation. J Neuroimmunol 274: 132-140, 2014.

59. Phillips S, Chokshi S, Riva A, Evans A, Williams R and Naoumov NV: CD8(+) T cell control of hepatitis B virus replication: Direct comparison between cytolytic and noncytolytic functions. J Immunol 184: 287-295, 2010.

60. Santana MA and Rosenstein Y: What it takes to become an effector T cell: The process, the cells involved, and the mechanisms. J Cell Physiol 195: 392-401, 2003

61. Sairanen T, Carpén O, Karjalainen-Lindsberg ML, Paetau A, Turpeinen U, Kaste M and Lindsberg PJ: Evolution of cerebral tumor necrosis factor-alpha production during human ischemic stroke. Stroke 32: 1750-1758, 2001

62. Domínguez-Roldán JM, García-Alfaro C, Jimenéz-González PI, Hernández-Hazañas F, Gascón Castillo ML and Egea Guerrero JJ: Brain death: Repercussion on the organs and tissues. Med Intensiva 33: 434-441, 2009 (In Spanish).

63. Barone FC and Feuerstein GZ: Inflammatory mediators and stroke: New opportunities for novel therapeutics. J Cereb Blood Flow Metab 19: 819-834, 1999.

64. Ferrarese C, Mascarucci P, Zoia C, Cavarretta R, Frigo M, Begni B, Sarinella F, Frattola L and De Simoni MG: Increased cytokine release from peripheral blood cells after acute stroke. J Cereb Blood Flow Metab 19: 1004-1009, 1999.

65. Soriano SG, Amaravadi LS, Wang YF, Zhou H, Yu GX, Tonra JR, Fairchild-Huntress V, Fang Q, Dunmore JH and Huszar D: Mice deficient in fractalkine are less susceptible to cerebral ischemia-reperfusion injury. J Neuroimmunol 125 : $59-65,2002$

66. Kumai Y, Ooboshi H, Takada J, Kamouchi M, Kitazono T, Egashira K, Ibayashi S and Iida M: Anti-monocyte chemoattractant protein-1 gene therapy protects against focal brain ischemia in hypertensive rats. J Cereb Blood Flow Metab 24: 1359-1368, 2004

67. Zhu Y, Yang GY, Ahlemeyer B, Pang L, Che XM, Culmsee C, Klumpp S and Krieglstein J: Transforming growth factor-beta 1 increases bad phosphorylation and protects neurons against damage. J Neurosci 22: 3898-3909, 2002.

68. Spera PA, Ellison JA, Feuerstein GZ and Barone FC: IL-10 reduces rat brain injury following focal stroke. Neurosci Lett 251: 189-192, 1998.

69. Vila N, Castillo J, Dávalos A, Esteve A, Planas AM and Chamorro A: Levels of anti-inflammatory cytokines and neurological worsening in acute ischemic stroke. Stroke 34: 671-675, 2003.

70. Savaş S, Delibaş N, Savaş C, Sütçü R and Cindaş A: Pentoxifylline reduces biochemical markers of ischemia-reperfusion induced spinal cord injury in rabbits. Spinal Cord 40: 224-229, 2002

71. Liu T, Clark RK, McDonnell PC, Young PR, White RF, Barone FC and Feuerstein GZ: Tumor necrosis factor-alpha expression in ischemic neurons. Stroke 25: 1481-1488, 1994. 
72. Uno $\mathrm{H}$, Matsuyama $\mathrm{T}$, Akita $\mathrm{H}$, Nishimura $\mathrm{H}$ and Sugita $\mathrm{M}$ Induction of tumor necrosis factor-alpha in the mouse hippocampus following transient forebrain ischemia. J Cereb Blood Flow Metab 17: 491-499, 1997

73. Offner H, Subramanian S, Parker SM, Afentoulis ME, Vandenbark AA and Hurn PD: Experimental stroke induces massive, rapid activation of the peripheral immune system. J Cereb Blood Flow Metab 26: 654-665, 2006.

74. Dziewulska D and Mossakowski MJ: Cellular expression of tumor necrosis factor a and its receptors in human ischemic stroke. Clin Neuropathol 22: 35-40, 2003.

75. Tarkowski E, Rosengren L, Blomstrand C, Wikkelsö C, Jensen C, Ekholm S and Tarkowski A: Intrathecal release of pro- and anti-inflammatory cytokines during stroke. Clin Exp Immunol 110: 492-499, 1997

76. Zaremba J and Losy J: Early TNF-alpha levels correlate with ischaemic stroke severity. Acta Neurol Scand 104: 288-295, 2001

77. Intiso D, Stampatore P, Zarrelli MM, Guerra GL, Arpaia G, Simone P, Tonali P and Beghi E: Incidence of first-ever ischemic and hemorrhagic stroke in a well-defined community of southern Italy, 1993-1995. Eur J Neurol 10: 559-565, 2003.

78. Hasturk A, Atalay B, Calisaneller T, Ozdemir O, Oruckaptan H and Altinors N: Analysis of serum pro-inflammatory cytokine levels after rat spinal cord ischemia/reperfusion injury and correlation with tissue damage. Turk Neurosurg 19: 353-359, 2009.

79. Lu K, Cho CL, Liang CL, Chen SD, Liliang PC, Wang SY and Chen HJ: Inhibition of the MEK/ERK pathway reduces microglial activation and interleukin-1-beta expression in spinal cord ischemia/reperfusion injury in rats. J Thorac Cardiovasc Surg 133: 934-941, 2007.

80. Mabuchi T, Kitagawa K, Ohtsuki T, Kuwabara K, Yagita Y, Yanagihara T, Hori M, Matsumoto M, Chang DI and del Zoppo GJ: Contribution of microglia/macrophages to expansion of infarction and response of oligodendrocytes after focal cerebral ischemia in rats. Stroke 31: 1735-1743, 2000.

81. Bernardes-Silva M, Anthony DC, Issekutz AC and Perry VH: Recruitment of neutrophils across the blood-brain barrier: The role of E- and P-selectins. J Cereb Blood Flow Metab 21: $1115-1124,2001$

82. Mazzotta G, Sarchielli P, Caso V, Paciaroni M, Floridi A, Floridi A and Gallai V: Different cytokine levels in thrombolysis patients as predictors for clinical outcome. Eur J Neurol 11: 377-381, 2004

83. Akuzawa S, Kazui T, Shi E, Yamashita K, Bashar AH and Terada H: Interleukin-1 receptor antagonist attenuates the severity of spinal cord ischemic injury in rabbits. J Vasc Surg 48: 694-700, 2008

84. Clark WM, Rinker LG, Lessov NS, Hazel K and Eckenstein F: Time course of IL-6 expression in experimental CNS ischemia. Neurol Res 21: 287-292, 1999.

85. Strle K, Zhou JH, Shen WH, Broussard SR, Johnson RW, Freund GG, Dantzer R and Kelley KW: Interleukin-10 in the brain. Crit Rev Immunol 21: 427-449, 2001.

86. Losy $\mathbf{J}$ and Zaremba $\mathrm{J}$ : Monocyte chemoattractant protein-1 is increased in the cerebrospinal fluid of patients with ischemic stroke. Stroke 32: 2695-2696, 2001.

87. Zaremba J, Ilkowski J and Losy J: Serial measurements of levels of the chemokines CCL2, CCL3 and CCL5 in serum of patients with acute ischaemic stroke. Folia Neuropathol 44: 282-289, 2006.

88. Takami S, Minami M, Nagata I, Namura S and Satoh M: Chemokine receptor antagonist peptide, viral MIP-II, protects the brain against focal cerebral ischemia in mice. J Cereb Blood Flow Metab 21: 1430-1435, 2001

89. Dimitrijevic OB, Stamatovic SM, Keep RF and Andjelkovic AV: Absence of the chemokine receptor CCR2 protects against cerebral ischemia/reperfusion injury in mice. Stroke 38: $1345-1353,2007$

90. Kärkelä J, Bock E and Kaukinen S: CSF and serum brain-specific creatine kinase isoenzyme (CK-BB), neuron-specific enolase (NSE) and neural cell adhesion molecule (NCAM) as prognostic markers for hypoxic brain injury after cardiac arrest in man. J Neurol Sci 116: 100-109, 1993
91. Yilmaz G and Granger DN: Leukocyte recruitment and ischemic brain injury. Neuromolecular Med 12: 193-204, 2010.

92.Zhang R, Chopp M, Zhang Z, Jiang N and Powers C: The expression of P- and E-selectins in three models of middle cerebral artery occlusion. Brain Res 785: 207-214, 1998.

93. Huang J, Choudhri TF, Winfree CJ, McTaggart RA, Kiss S, Mocco J, Kim LJ, Protopsaltis TS, Zhang Y, Pinsky DJ, et al: Postischemic cerebrovascular E-selectin expression mediates tissue injury in murine stroke. Stroke 31: 3047-3053, 2000.

94. Ishikawa M, Cooper D, Russell J, Salter JW, Zhang JH, Nanda A and Granger DN: Molecular determinants of the prothrombogenic and inflammatory phenotype assumed by the postischemic cerebral microcirculation. Stroke 34: 1777-1782, 2003.

95. Lindsberg PJ, Carpén O, Paetau A, Karjalainen-Lindsberg ML and Kaste M: Endothelial ICAM-1 expression associated with inflammatory cell response in human ischemic stroke. Circulation 94: 939-945, 1996

96. Kitagawa K, Matsumoto M, Mabuchi T, Yagita Y, Ohtsuki T, Hori $\mathrm{M}$ and Yanagihara T: Deficiency of intercellular adhesion molecule 1 attenuates microcirculatory disturbance and infarction size in focal cerebral ischemia. J Cereb Blood Flow Metab 18: 1336-1345, 1998.

97. Bernard SA, Gray TW, Buist MD, Jones BM, Silvester W, Gutteridge G and Smith K: Treatment of comatose survivors of out-of-hospital cardiac arrest with induced hypothermia. N Engl J Med 346: 557-563, 2002

98. Yenari MA and Han HS: Influence of hypothermia on post-ischemic inflammation: Role of nuclear factor kappa B (NFkappaB). Neurochem Int 49: 164-169, 2006.

99. Callaway CW, Rittenberger JC, Logue ES and McMichael MJ Hypothermia after cardiac arrest does not alter serum inflammatory markers. Crit Care Med 36: 2607-2612, 2008.

100. Cilio MR and Ferriero DM: Synergistic neuroprotective therapies with hypothermia. Semin Fetal Neonatal Med 15: 293-298, 2010

101. Plane JM, Shen Y, Pleasure DE and Deng W: Prospects for minocycline neuroprotection. Arch Neurol 67: 1442-1448, 2010

102. Chu LS, Fang SH, Zhou Y, Yin YJ, Chen WY, Li JH, Sun J, Wang ML, Zhang WP and Wei EQ: Minocycline inhibits 5-lipoxygenase expression and accelerates functional recovery in chronic phase of focal cerebral ischemia in rats. Life Sci 86: 170-177, 2010.

103. Yrjänheikki J, Tikka T, Keinänen R, Goldsteins G, Chan PH and Koistinaho J: A tetracycline derivative, minocycline, reduces inflammation and protects against focal cerebral ischemia with a wide therapeutic window. Proc Natl Acad Sci USA 96: 13496-13500, 1999.

104.Lampl Y, Boaz M, Gilad R, Lorberboym M, Dabby R, Rapoport A, Anca-Hershkowitz M and Sadeh M: Minocycline treatment in acute stroke: An open-label, evaluator-blinded study. Neurology 69: 1404-1410, 2007.

105. Ohsawa I, Ishikawa M, Takahashi K, Watanabe M, Nishimaki K, Yamagata K, Katsura K, Katayama Y, Asoh S and Ohta S: Hydrogen acts as a therapeutic antioxidant by selectively reducing cytotoxic oxygen radicals. Nat Med 13: 688-694, 2007.

106. Hayashida K, Sano M, Kamimura N, Yokota T, Suzuki M, Maekawa Y, Kawamura A, Abe T, Ohta S, Fukuda K, et al: $\mathrm{H}(2)$ gas improves functional outcome after cardiac arrest to an extent comparable to therapeutic hypothermia in a rat model. J Am Heart Assoc 1: e003459, 2012.

107. Huang G, Zhou J, Zhan W, Xiong Y, Hu C, Li X, Li X, Li Y and Liao X: The neuroprotective effects of intraperitoneal injection of hydrogen in rabbits with cardiac arrest. Resuscitation 84: 690-695, 2013

108. Vaughan CJ and Delanty N: Neuroprotective properties of statins in cerebral ischemia and stroke. Stroke 30: 1969-1973, 1999. 